Mechanics of Machines 
The English Language Book Society is funded by the Overseas Development Administration of the British Government. It makes available low-priced, unabridged editions of British publishers' textbooks to students in developing counries. Below is a list of some other books on mechanical engineering published under the ELBS imprint.

Case and Chilver

Strength of Materials and Structures Edward Arnold

Douglas, Gasiorek and Swaffield

Fluid Mechanics

Longman

Gibbs

An Introduction to CNC Machining

Cassell

Hannah and Hillier

Applied Mechanics

Longman

Hughes and Martin

Basic Engineering Mechanics

Macmillan

Lissaman and Martin

Principles of Engineering Production

Edward Arnold

Massey

Mechanics of Fluids

Chapman \& Hall

Morrison and Crossland

An Introduction to the Mechanics of

Machines

Longman

Rogers and Mayhew

Engineering Thermodynamics

Longman

Ryder

Strength of Materials

Macmillan 


\section{Mechanics of Machines}

\section{Second Edition}

\section{G. H. RYDER}

Formerly Principal Lecturer, Royal Military College of Science, Shrivenham

\section{D. BENNETT}

Senior Lecturer, Royal Military College of Science, Shrivenham

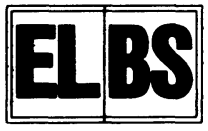

English Language Book Society/Macmillan 


\section{Macmillan Education Ltd}

Houndmills, Basingstoke, Hampshire RG21 2XS

Companies and representatives throughout the world

(C) G. H. Ryder and M. D. Bennett 1975, 1990

All rights reserved. No part of this publication may be reproduced or transmitted, in any form or by any means, without written permission.

First edition 1975

Reprinted 1978, 1980, 1982, 1986

Second edition 1990

ELBS edition first published 1978

Reprinted 1980, 1983, 1986, 1987

ELBS edition of second edition 1990

ISBN 978-0-333-53696-4 ISBN 978-1-349-21112-8 (eBook)

DOI 10.1007/978-1-349-21112-8 


\section{Contents}

Preface to the First Edition

Preface to the Second Edition vii

Part I: Principles 1

1 Introduction 3

2 Forces and Equilibrium 11

3 Kinematics $\quad 40$

4 Kinetics $\quad 69$

5 Work and Energy $\quad 88$

6 Impulse and Momentum 103

Part II: Applications 123

7 Kinematics of Mechanisms 125

8 Friction and Lubrication in Machines 150

9 Toothed Gears 182

10 Geared Systems 201

11 Kinetics of Machine Elements 225

12 Balancing of Machines 243

13 Vibrations of Single-degree-of-freedom Systems 262

14 Vibrations of Multi-degree-of-freedom Systems 282

15 Lateral Vibrations and Whirling Speeds 294

16 Robotics and Control 310

Index 333 


\section{Preface to the First Edition}

The present text has evolved and grown from an earlier book by one of the authors entitled Theory of Machines through Worked Examples. When it was decided that the time had come for conversion to SI units, the opportunity was taken to change the format from a collection of problems to a conventional student-textbook. In the event, this has enabled a more comprehensive and self-contained work to be produced and the title has been modified to reflect this change. The book has been completely rewritten under co-authorship and this has provided an opportunity to incorporate fresh ideas in teaching and presentation of the subject.

The scope of the book is intended to give adequate coverage to students working for H.N.C. and H.N.D. in engineering, and to first- and second-year students of a full-time honours degree course. For the latter it will form a solid base for more advanced study, in topics such as machine design, vibrations and control, depending on the specialisation adopted by individual universities and polytechnics.

The book begins with a chapter on the fundamental principles of mechanics of machines and, although this is necessarily extensive, a conscious effort has been made to deal only with those aspects which are essential to the understanding of later work. Throughout the book the aim has been to illustrate the theory by means of engineering applications over a wide field. Numerical examples have been carefully selected to give the reader a realistic appreciation of actual system parameters and performance.

The chapters then follow a traditional sequence, dealing first with the kinematics of machines, and with force and velocity relations in systems where inertia effects may be neglected. Subsequently, attention is turned to the analysis of specific machine elements such as clutches, belt drives and gears. This is followed by consideration of inertia effects in machines, leading naturally to the problems of balancing rotating and reciprocating masses. Three chapters are devoted to vibrations, both free and forced, of single- and multi-degree-of-freedom systems. The book ends with a chapter on the principles and applications of control in mechanical engineering. 


\section{Preface to the Second Edition}

Recent changes in the structure of mathematics and physics courses in secondary schools, and the depth of coverage given, have indicated that some complementary changes to the Mechanics of Machines text were appropriate. The main differences between the first and second editions occur in the sections dealing with the basic principles of mechanics, which now appear as Part $I$ and are arranged in six chapters instead of the original single chapter. This allows the individual principles to be more readily identified and systematically studied. At the same time, more worked examples have been included, and some topics have been developed a little further, notably in the new chapter on impulse and momentum.

Part II contains the original chapters that described some of the applications of the principles discussed in Part I. Again, the opportunity has been taken to add to some of these chapters. A section on strength and wear has been included with toothed gears, cams have been included as a further example of machine elements, and engine balance has been extended to Vee-engine layouts. The final chapter on control has been enlarged to include the application of control systems to robotics.

Each chapter in the second edition concludes with a summary of the important results for easy reference.

While making these changes, care has been taken not to change the general approach, and the expected readership is the same. 